Meerhoff, T.J., Paget, W.J., Kimpen, J.L., Schellevis, F. Variation of respiratory syncytial virus and the relation with meteorological factors in different winter seasons. Pediatric Infectious Disease Journal: 2009, 28(10), 860866

\begin{tabular}{|l|l|}
\hline Postprint Version & 1.0 \\
\hline Journal website & $\underline{\text { http://dx.doi.org/10.1097/INF.0b013e3181a3e949 }}$ \\
\hline Pubmed link & $\underline{\text { http://www.ncbi.nlm.nih.gov/pubmed/20118684 }}$ \\
\hline DOI & $10.1097 /$ INF.0b013e3181a3e949 \\
\hline
\end{tabular}

This is a NIVEL certified Post Print, more info at http://www.nivel.eu

\title{
Variation of Respiratory Syncytial Virus and the Relation With Meteorological Factors in Different Winter Seasons
}

\author{
Meerhoff, Tamara J. MSC*; Paget, John W. PhD*; Kimpen, JAN L. MD, PhD†; SCHelLeVis, \\ FRANÇOIS MD, PHD*‡ \\ Author Information \\ From the *NIVEL (Netherlands Institute for Health Services Research), Utrecht, the Netherlands; \\ †Department of Pediatrics, Wilhelmina Children's Hospital, University Medical Centre, Utrecht, the \\ Netherlands; and ‡Department of General Practice, EMGO Institute, VU University Medical Centre, \\ Amsterdam, the Netherlands. \\ Address for correspondence: Tamara J. Meerhoff, MSc, NIVEL (Netherlands Institute for Health Services \\ Research), PO Box 1568, 3500 BN Utrecht, the Netherlands. E-mail: t.meerhoff@nivel.nl.
}

\begin{abstract}
Background: Respiratory syncytial virus (RSV) is the most important viral agent causing severe respiratory disease in infants and children. In temperate climates, RSV activity typically peaks during winter. We have described the seasonal variation in RSV activity and investigated which meteorological variables are related to RSV outbreaks for different time lags.

Methods: Eleven laboratories in the Netherlands collected data on RSV during the period 1998-2005. Meteorological data were obtained from the Royal Netherlands Meteorological Institute. General linear methods were used to determine the relative contribution of meteorological conditions to reported RSV cases in the winter period. Time lags up to 4 weeks were included to assess a possible delayed weather effect in relation to RSV activity.

Results: Onset of RSV activity occurred around week 44 and activity peaked around week 52. Timing of peak activity was very consistent over the study period. Relative humidity was positively associated with RSV activity for all time lags, indicating more RSV when relative humidity increased. Minimum temperature was negatively associated with RSV activity and cloud cover was positively related with RSV activity. Interaction $(\mathrm{P}<0.06)$ between minimum temperature and relative humidity was observed for a lag of 0,1 , and 2 weeks, indicating that the combination of low temperature and high humidity contributes more to RSV activity than temperature and humidity alone.

Conclusions: Relative humidity, minimum temperature, and cloud cover are important predictors of RSV activity in the Netherlands, with the effect of relative humidity being most consistent.
\end{abstract}

Respiratory syncytial virus (RSV) is the most important viral agent causing severe respiratory disease in infants and children worldwide.1 Most children have been infected at least once by the age of 2 and reinfections occur throughout life.2 The symptoms of an RSV infection range from a very mild illness to 
Meerhoff, T.J., Paget, W.J., Kimpen, J.L., Schellevis, F. Variation of respiratory syncytial virus and the relation with meteorological factors in different winter seasons. Pediatric Infectious Disease Journal: 2009, 28(10), 860866

serious lower respiratory tract infections including bronchiolitis and pneumonia. Although infrequently recognized, RSV is common in adults and can be the cause of severe illness especially in the elderly. 3 The average annual rate of RSV-associated hospitalization has been reported to be 3 (range: 2-6) per 1000 children and 17 (range: 12-34) per 1000 children under the age of 6 months.4 Mortality rates in children are low, RSV attributed deaths have been estimated at 8.4 per 100,000 population. More than half of the attributed deaths in children aged 1 month to 14 years occurred in babies aged 1 to 12 months.5

In temperate climates, RSV activity typically peaks during the winter. Epidemics are related to geographic and climatic factors, but it is not clear whether this is related to the spread of virus, indoor crowding, or immunologic susceptibility of the population.6 For the influenza virus, another respiratory virus that circulates during wintertime, transmission is dependent on relative humidity and temperature. 7 This evidence supports the role of weather conditions in the dynamics of influenza and may also be applicable for RSV transmission. However, the mode of transmission differs slightly between the 2 viruses. RSV is transmitted by large-particle aerosols and by direct contact with RSV in solutions of human secretions,8 whereas influenza is spread via small droplets as people sneeze, cough, or talk.

Meteorological conditions such as temperature, relative humidity, and UV-B radiation have recently been described in relation to RSV epidemics.6,9,10 A study performed in Spain indicated that low levels of temperature and low absolute humidity were positively associated with the number of RSV cases and low absolute humidity was independently related to RSV infection.9 Worldwide, RSV peaks at 2 temperature intervals: between $2^{\circ} \mathrm{C}$ and $6^{\circ} \mathrm{C}$ in temperate regions and between $24^{\circ} \mathrm{C}$ and $30^{\circ} \mathrm{C}$ in tropical regions. RSV activity was greatest at $45 \%$ to $65 \%$ relative humidity and UV-B radiance was inversely related to the number of RSV cases.10 So far, mainly crude associations between RSV activity and weather have been assessed and correlations between the meteorological variables have not always been taken into account. In addition, weather models have usually not included a time delay effect on RSV, while one would expect some delay between weather changes and RSV activity.

RSV epidemics occur yearly but may alternate in occurrence between midwinter and early spring.11,12 A biannual rhythm with an early RSV season followed by a late season has been described for Finland, Germany, and Croatia.12-14 Year-to-year national and regional variability in the RSV season onset and offset occurs in the United States.15 Appropriately timed diagnostic testing can provide data that indicate when the RSV season begins nationally and regionally, information that is critical in determining when to begin RSV prophylaxis for infants at high risk for infection. The monoclonal antibody palivizumab offers protection against complications, and the first of the 5 monthly doses should be administered before onset of community RSV activity. In this article, we investigate which meteorological factors can predict RSV outbreaks and describe the year-to-year variation of RSV activity in the Netherlands. To adjust for the incubation time and possible delayed weather effects, 4 time lags were included in the model to assess the relation of weather variables with RSV activity.

\section{METHODS}

\section{Design}

The role of meteorological variables on RSV was assessed during RSV active periods in 8 consecutive years (1998-2005). Data about RSV activity were derived from a central computer-based data system, the Infectious diseases Surveillance Information System (ISIS), based at the National Institute for Public Health and the Environment. Meteorological data were available on a daily basis for 10 variables and collected by the Royal Netherlands Meteorological Institute. We used the number of RSV confirmed cases per week as the outcome variable and investigated whether there was an association between weather variables and RSV in the Netherlands.

\section{Selection of RSV Active Periods}

All analyses were restricted to RSV active periods, starting at week 40 and ending in week 20 of the following year. The season onset and offset criteria for RSV were based on those of the National Respiratory and Enteric Virus Surveillance System.16 We defined the week of onset as the first of 2 
Meerhoff, T.J., Paget, W.J., Kimpen, J.L., Schellevis, F. Variation of respiratory syncytial virus and the relation with meteorological factors in different winter seasons. Pediatric Infectious Disease Journal: 2009, 28(10), 860866

consecutive weeks in which at least $10 \%$ of the tested samples tested positive for RSV and a minimum of 10 samples were tested in that week. Offset was defined as the last of 2 consecutive weeks with at least $10 \%$ of the samples tested positive for RSV and a minimum of 10 samples tested in that week. All seasons included a week 53 that usually comprised 1 or 2 days. For defining the onset and offset, we have compared the threshold of 10 tests per week to a threshold of 20 tests per week. The threshold of 20 samples showed little difference for the onset, but large difference in defining the offset. We defined the threshold at 10 tests per week, which was most sensitive in determining the onset and offset of the RSV active period. The duration was defined as the number of weeks from onset to offset.

\section{RSV Data}

Data were derived from ISIS. This system automatically collects data on a daily basis on RSV from regional laboratories and/or hospitals in the Netherlands and these were mainly concentrated in the middle and Southern regions of the Netherlands (Fig. 1). Data from 11 laboratories were included and contained information on the age of the patient, gender, 4 digit postal code, type of material sampled, and the laboratory method. Both positive and negative test results were recorded. All test results were anonymously and uniquely coded for each patient.

To estimate the population coverage of the laboratories, we looked at the laboratories that reported to ISIS in $2000(n=9)$ and compared this to the total number of laboratories $(n=58)$ in the Netherlands as a whole.17 The coverage of the ISIS laboratories was estimated at 2.4 million, which covers around $16 \%$ of the Dutch population. It was assumed that all patients with severe RSV infection in the region would be picked up by the regional laboratory. Participating laboratories generally used 1 or 2 diagnostic methods: (in) direct immunofluorescence $(n=6)$, culture $(n=5)$, antigen detection $(n=3)$, or enzyme-linked immunosorbent assay $(n=2)$. In the Netherlands, an attempt is usually made to come to an RSV diagnosis in hospitalized bronchiolitic infants. Diagnostic tests are rarely performed in nonhospitalized children with respiratory symptoms.

\section{[FIGURE 1]}

\section{Meteorological Data}

The Royal Netherlands Meteorological Institute collects daily meteorological data in the Netherlands. Data were obtained from a centrally located weather station (De Bilt) and included: prevailing wind direction in degrees (360 $=$ North, $180=$ South, $270=$ West, $0=$ calm/variable), daily mean wind speed in $0.1 \mathrm{~m} / \mathrm{s}$, daily mean temperature in $0.1^{\circ} \mathrm{C}$, minimum temperature in $0.1^{\circ} \mathrm{C}$, maximum temperature in $0.1^{\circ} \mathrm{C}$, sunshine duration in 0.1 hour, percentage of maximum possible sunshine duration, daily precipitation amount in $0.1 \mathrm{~mm}(-1$ for $<0.05 \mathrm{~mm})$, daily mean surface air pressure in $0.1 \mathrm{hPa}$, cloud cover in octants $(0=$ no clouds $-9=$ sky invisible), and daily mean relative atmospheric humidity in percentage.

The absolute humidity is directly related to the temperature and relative humidity, and was calculated by multiplying relative humidity with water vapor, as has been previously described in Lapena et al.9 For the prevailing wind direction, we categorized the 4 wind directions and calculated the most frequently observed wind direction in the form of the modus per week. The weekly sum of precipitation data was used, and for all other weather variables the data were aggregated to the week average value.

\section{Data Analysis}

The outcome variable was the number of positive cases of RSV per week during RSV active periods. Multiple linear regression analysis was performed on all weekly aggregated weather variables and the number of cases of RSV for all years. Variables were checked for correlation. Poisson and negative binomial regression analyses were performed in addition to the linear regression analysis. Week 53 consisted of 1 or 2 days and the RSV cases for this week were extrapolated to a whole week for the analysis. Weather data for week 53 were not extrapolated, because all weather variables, except precipitation, were aggregated to the week average value. 
Meerhoff, T.J., Paget, W.J., Kimpen, J.L., Schellevis, F. Variation of respiratory syncytial virus and the relation with meteorological factors in different winter seasons. Pediatric Infectious Disease Journal: 2009, 28(10), 860866

Because the incubation time of RSV infection is 2 to 7 days and there might be a delay in the weather effect in relation to RSV infection, different time lags (no lag, lag of 1 week, lag of 2 weeks, lag of 3 weeks, lag of 4 weeks) were included in the regression analyses. The descriptive and linear regression analyses were performed using SPSS 14. STATA 9 was used for the Poisson and negative binomial regression analysis and the robust option was used to adjust for heterogeneity in the model.18 Significance was concluded when $P<0.05$.

The interaction between relative humidity and minimum temperature was calculated by multiplying the 2 variables. The minimum temperature was multiplied by -1 before calculating the interaction because this variable was negatively associated with RSV activity and opposite to the association of RSV with relative humidity. Significance of interaction was concluded when $P<0.1$.

\section{RESULTS}

\section{Demographics}

Data from 11 laboratories for the period 1998-2005 were included in the analyses. A total of 10672 tests were performed during the RSV active periods. Baseline characteristics of the participating laboratories can be found in Table 1. Most cases were infants aged below 6 months and more boys than girls tested positive for RSV which corresponds with previous studies.19,20

\section{Seasonal Trends}

The number of participating laboratories increased from 5 in 1998 to 11 in 2002-2003 (Table 2). In 2005, the season contained data only up to week 52, and therefore fewer cases were reported for this season. The onset of RSV activity occurred around week 44, peaked around week 52, and was quite consistent for the study period. The duration and offset differed somewhat by season. Relative humidity and cloud cover were similar for the different seasons around both the onset and the peak of RSV activity. Some differences in the minimum temperature are observed for the different winters with a generally lower temperature around the peak (Table 2).

\section{[TABLE 2]}

\section{Association With Meteorological Factors}

The consistent onset would suggest some factor that triggers the RSV activity. This factor may be related to the weather. We assessed whether the weather variables were correlated with the weekly number of RSV cases. The first step was to assess the correlation between weather variables. A strong correlation $(r>0.8)$ was observed for (1) minimum temperature and absolute humidity, (2) relative humidity and sunshine duration, and (3) cloud cover and sunshine duration. Additionally, correlation was observed for the 3 temperature variables: minimum, mean, and maximum temperature. We therefore excluded the following variables from the analyses: absolute humidity, sunshine duration, mean temperature, and maximum temperature. The minimum temperature and relative humidity have been suggested as predictors of RSV activity in earlier studies 9,10 and were included in the analysis, as well as the other weather variables that did not present a high correlation with other weather variables.

The wind speed, modal prevailing wind direction, minimum temperature, precipitation, air pressure, cloud cover, and relative humidity were assessed on the relation with weekly number of RSV cases (Pearson correlation). The relative humidity $(r=0.340)$, minimum temperature $(r=-0.338)$, and cloud cover $(r=$ 0.221 ) were significantly correlated with the weekly number of RSV cases and this finding was observed for all time lags, although the $r$ value decreased with increasing time lag for relative humidity and cloud cover.

We also emphasized to illustrate the relation of weather variables with RSV activity. The weekly number of RSV-positive patients is presented for the weeks 40 to 20 during 1998-2005, as well as the weather variables minimum temperature, relative humidity, and cloud cover (Fig. 2). For the 3 weather variables the weekly values were quite variable. The temperature at the beginning and end of the season was higher than in the middle of the season when RSV activity was at its peak. A general drop in temperature around the RSV peak was most obvious for the period 2000-2003. Relative humidity was generally higher around the 
Meerhoff, T.J., Paget, W.J., Kimpen, J.L., Schellevis, F. Variation of respiratory syncytial virus and the relation with meteorological factors in different winter seasons. Pediatric Infectious Disease Journal: 2009, 28(10), 860866

RSV peak, while at the end of the season a sudden drop in relative humidity can be observed. The figure presenting cloud cover and RSV also shows that RSV peaked around the time the highest cloud cover was reported. Although the weekly variation of the variables makes it difficult to track any subtle effects, this figure allows us to visualize a relation of meteorological factors with RSV.

Multiple linear regression analysis was initially performed for each of the years separately (data not shown). At least one of the meteorological factors, minimum temperature, relative humidity, and cloud cover, was significantly associated with RSV activity in 7 of 8 winter seasons: 1998-1999, 2000-2001 to 2004-2005. Relative humidity was a significant factor in the winter of 2000-2001, 2001-2002, 2003-2004, 2004-2005 for multiple time lags. Temperature was significantly associated with RSV in 4 winters, varying from lag $=0$ to lag $=2$. Cloud cover was significantly associated with RSV in 3 winters for lag $=0$ and/or $\operatorname{lag}=1$.

For all seasons together, we performed multiple linear regression analysis and evaluated the model with the number of RSV cases as dependent variable, and the relative humidity, minimum temperature, and cloud cover as independent variables. This model explained about $21 \%$ of the variance in RSV cases $\left(R^{2}=\right.$ 0.209; Table 3). When looking at the same model for different time lags, which ranged from 1 to 4 weeks, the effect of the weather variables decreased: $R^{2}$ from 0.209 to 0.165 .

The relation of temperature with RSV was negative, indicating more RSV activity when the temperature decreased. A positive relation was observed for relative humidity and to some extent for cloud cover, indicating more RSV when the relative humidity or cloud cover increased. The minimum temperature contributed to the RSV cases for most time lags ( $0-3$ weeks). The relative humidity still played an important role at the time lag of 4 weeks (Table 3). Cloud cover was borderline significant $(P=0.051)$ in relation with RSV in the first time lag. To investigate whether the effect of one meteorological variable on RSV activity depends on the level of a second weather variable, we calculated the interaction effect of minimum temperature and relative humidity on RSV activity and included this in the regression model (Table 4). There was an interaction effect at lag $=0(P=0.018), \operatorname{lag}=1(P=0.053)$, and lag $=2(P=$ 0.059 ), and the role of temperature was reduced and borderline significant at lag $=1$.

In addition to multiple linear regression analysis, Poisson regression was carried out as count data are highly non-normally distributed and are better estimated by Poisson regression. The results of the Poisson regression analysis were identical for the minimum temperature and relative humidity as performed by the linear analysis (data not shown). In the Poisson regression cloud cover was a significant factor at no lag ( $P$ $<0.01)$ and a lag of 1 week $(P<0.05)$ where the linear regression found a borderline significant effect at no lag $(P=0.051)$. Poisson regression assumes that the mean and the variance are the same; our dataset did not fit this assumption. Therefore, we also performed negative binomial regression, which is better fit for overdispersed data. For all 3 meteorological factors the previous Poisson analysis was confirmed.

\section{[FIGURE 2] [TABLE 3] [TABLE 4]}

\section{DISCUSSION}

Our data showed that relative humidity, minimum temperature, and cloud cover were important predictors of RSV activity for different time lags in the Netherlands. The effect of the time lag is relevant and the 3 meteorological factors contributed most to the model at lags 0 to 2 weeks, indicated by the $R^{2}$ explaining the variance in RSV cases for about $22 \%$. The effect of meteorological factors was not statistically significant for all individual winter seasons, but this was expected due to the loss of power in particular the 1998-1999 and 1999-2000 winters when a low number of samples were tested for RSV in these periods.

Most obvious was the positive relation of RSV with the relative humidity that showed significant association for all time lags, also after adding an interaction term into the regression model. Minimum temperature was inversely related to RSV and this parameter contributed to RSV activity in 3 of the 4 time lags. After addition of the interaction parameter into the model the effect of minimum temperature decreased. The interaction found between relative humidity and minimum temperature highlighted that the combination of the 2 parameters have a stronger impact on RSV activity than each of the parameters alone and better fitted the model as $R^{2}$ was higher. 
Meerhoff, T.J., Paget, W.J., Kimpen, J.L., Schellevis, F. Variation of respiratory syncytial virus and the relation with meteorological factors in different winter seasons. Pediatric Infectious Disease Journal: 2009, 28(10), 860866

The consistent peak week of RSV activity observed for the Netherlands has also been reported for the United Kingdom, but differs from reports made for Croatia and Finland. In Croatia and Finland RSV outbreaks occur in every second year causing a mild spring peak, followed by a larger outbreak in the winter during the same year. For Croatia the large RSV outbreak was inversely related to the temperature and directly to humidity.13 But the subsequent winter is rather silent, and the role of meteorological factors did not explain the timing of RSV outbreak in Croatia. Differences in outbreaks between countries may be related to the climate and population density. The Netherlands has a temperate, marine climate, similar to the United Kingdom. Croatia has a Mediterranean and continental climate, while Finland has a cold temperate climate. Population density in the Netherlands is 395 inhabitants/km,2 while in Finland it is 16 inhabitants $/ \mathrm{km} 2$ and in Croatia 81 inhabitants/km.2,21 The silent winter might be explained by the effect of the low population and thereby a low number of susceptible children, which lowers spread of RSV.

The relation between RSV activity and low minimum temperature may indicate that a low temperature enhances virus transmission. It has been described in earlier studies that transmission of RSV is inversely related to temperature in cooler climates and this may be a result of increased stability of the virus in the secretions in the colder environment.10 A limited amount of literature is available on RSV transmission and the role of temperature and humidity, but has been investigated for influenza, also a typical winter disease. Lowen et al 7 found that influenza virus transmission is dependent on relative humidity and temperature and provided direct, experimental evidence to support the role of weather conditions in the dynamics of influenza. They found increased shedding of virus and enhanced transmission at $5^{\circ} \mathrm{C}$ when compared with $20^{\circ} \mathrm{C}$. Research on the stability of RSV has been described by Rechsteiner and Winkler,22 they prepared stable aerosols of RSV and kept them at different relative humidity. Virus recoveries were highest at high relative humidity and the stability of the aerosol was maximal at $60 \%$ relative humidity. This indicates that humidity indeed plays an important role and may affect transmission of the virus.

Our study also highlighted a probable effect of cloud cover on RSV. To our knowledge, no other study has included this meteorological variable in the analysis. However, UV B has also been reported to predict RSV activity.10 A possible explanation is that UV B radiance could interfere with the spread of RSV by inactivating the virus. UV B could also indirectly affect RSV activity by stimulating vitamin D on the outcome of RSV infection. A number of studies have indicated that vitamin D deficient children are at greater risk of having respiratory infections.23,24 In our study, we did not include UV B, however, one might expect some relation between UV B and cloud cover. Moise and Aynsley indicated that increasing cloud cover decreases the UV B because of the increase in the diffuse fraction of the radiation, and for the Netherlands it has been estimated that clouds generally decreased the UV radiation by $34 \%$ in the period 1998-2005.25,26 The direction of the relation of cloud cover corresponds to the inverse relationship of RSV activity and UV B that has been described by Yusuf et al.10

One limitation of this study was the number of laboratories that reported data to ISIS; the number varied by year and thereby affected the number of tests performed for RSV diagnosis. In addition, the methods used differed somewhat by laboratory, and did not include the most sensitive methods such as real-time polymerase chain reaction. Another limitation concerns the analysis of meteorological data as we chose to calculate weekly averages for most factors and modus for the wind direction. For some variables the values can differ considerably by day, for example, wind direction, and our procedure may have reduced sensitivity to pick up the daily variation, and smoothing the effect of the weather variables on RSV. Finally, we used meteorological data from a central point, "the Bilt," in the Netherlands, while using RSV data from predominantly the Southern and Eastern provinces of the country. However, we do not think that regional differences in weather would have affected our main outcomes, as distances are quite small in the Netherlands. In addition, although some minor daily variations in meteorological factors exist, we do not think that the slight differences in temperature and humidity have an effect on the study outcome, also because data were averaged to a weekly value.

Factors other than meteorological conditions contribute to the spread of RSV. Meteorological factors in our study explained part (21\%) of the variation in RSV cases; a driving factor for RSV activity is the immunity against RSV among the susceptible young population. Furthermore, weather factors might also have their effect through the behavior of the population when RSV is circulating. One practical explanation could be that in cold, rainy, and cloudy days people stay inside and this causes more indoor crowding and transmission. In addition, cold weather may also have an effect on the respiratory tract, as cold air may induce broncho-constriction.27,28 
Meerhoff, T.J., Paget, W.J., Kimpen, J.L., Schellevis, F. Variation of respiratory syncytial virus and the relation with meteorological factors in different winter seasons. Pediatric Infectious Disease Journal: 2009, 28(10), 860866

The onset of RSV activity was very consistent for the 8 winters and was around week 44, which is similar to that described for the UK where the incidence of acute bronchitis and bronchiolitis in young children revealed a consistent increase in RSV activity during week 43 each year.29 Practical implications of our study relate to timing of RSV prophylaxis. The monoclonal antibody palivizumab offers protection against complications, and the first of the 5 monthly doses should be administered before onset of community RSV activity. Our findings of a consistent increase in RSV around week 44 in the Netherlands could be used for RSV prophylaxis, preferably combined with real-time RSV surveillance.

The theoretical implications of our study are that relative humidity, minimum temperature, and cloud cover are important predictors of RSV in the Netherlands and may be related to transmission of the virus. More experimental research however is needed. In summary, we have found that onset of RSV activity is quite consistent in the Netherlands and that relative humidity, minimum temperature, and cloud cover predict RSV activity in the Netherlands, with the effect of relative humidity being most consistent.

\section{ACKNOWLEDGMENTS}

The authors thank Simone van der Plas (RIVM, The Netherlands) from the ISIS project and all participating laboratories and hospitals for providing their data: Bosch Medisch Centrum, Den Bosch; Canisius Wilhelmina Hospital, Nijmegen; Laboratory for Infectious Diseases, Groningen; Laboratorium Microbiologie Twente Achterhoek, Enschede; Ruwaard van Putten Hospital, Spijkenisse; St. Antonius Hospital, Nieuwegein; St. Elizabeth Hospital, Tilburg; St. Jans Gasthuis, Weert; St. Laurentius Hospital, Roermond; Streeklaboratorium Zeeland, Terneuzen; Streeklaboratorium Zeeland, Goes. The authors also thank Raymond Kenens (NIVEL) for providing the GIS map, Louis Bont for his comments to this manuscript, and Peter Spreeuwenberg (NIVEL) for providing statistical assistance.

\section{REFERENCES}

1. Crowcroft NS, Cutts F, Zambon MC. Respiratory syncytial virus: an underestimated cause of respiratory infection, with prospects for a vaccine.

Commun Dis Public Health. 1999;2:234 -241. 2. Glezen WP, Taber LH, Frank AL, et al. Risk of primary infection and reinfection with respiratory syncytial virus. Am J Dis Child. 1986;140:543- 546.

3. Falsey AR, Walsh EE. Respiratory syncytial virus infection in adults. Clin Microbiol Rev. 2000;13:371384.

4. Hall $\mathrm{CB}$, Weinberg GA, Iwane MK, et al. The burden of respiratory syncytial virus infection in young children. N Engl J Med. 2009;360:588- 598.

5. Fleming DM, Pannell RS, Cross KW. Mortality in children from influenza and respiratory syncytial virus. J Epidemiol Community Health. 2005;59: 586-590.

6. Stensballe LG, Devasundaram JK, Simoes EA. Respiratory syncytial virus epidemics: the ups and downs of a seasonal virus. Pediatr Infect Dis J. 2003;22:S21-S32.

7. Lowen AC, Mubareka S, Steel J, et al. Influenza virus transmission is dependent on relative humidity and temperature. PLoS Pathog. 2007;3: 1470-1476.

8. Hall CB, Douglas RG Jr. Modes of transmission of respiratory syncytial virus. J Pediatr. 1981;99:100 103.

9. Lapena S, Robles MB, Castanon L, et al. Climatic factors and lower respiratory tract infection due to respiratory syncytial virus in hospitalized infants in northern Spain. Eur J Epidemiol. 2005;20:271-276.

10. Yusuf S, Piedimonte G, Auais A, et al. The relationship of meteorological conditions to the epidemic activity of respiratory syncytial virus. Epidemiol Infect. 2007;135:1077-1090.

11. Glezen P, Denny FW. Epidemiology of acute lower respiratory disease in children. N Engl J Med. 1973;288:498 -505.

12. Terletskaia-Ladwig E, Enders G, Schalasta G, et al. Defining the timing of respiratory syncytial virus (RSV) outbreaks: an epidemiological study. BMC Infect Dis. 2005;5:20.

13. Mlinaric-Galinovic G, Welliver RC, Vilibic-Cavlek T, et al. The biennial cycle of respiratory syncytial virus outbreaks in Croatia. Virol J. 2008;5:18.

14. Waris M. Pattern of respiratory syncytial virus epidemics in Finland: two-year cycles with alternating prevalence of groups A and B. J Infect Dis. 1991;163:464-469.

15. Mullins JA, Lamonte AC, Bresee JS, et al. Substantial variability in community respiratory syncytial virus season timing. Pediatr Infect Dis J. 2003;22:857- 862. 
Meerhoff, T.J., Paget, W.J., Kimpen, J.L., Schellevis, F. Variation of respiratory syncytial virus and the relation with meteorological factors in different winter seasons. Pediatric Infectious Disease Journal: 2009, 28(10), 860866

16. Panozzo CA, Fowlkes AL, Anderson LJ. Variation in timing of respiratory syncytial virus outbreaks: lessons from national surveillance. Pediatr Infect Dis J. 2007;26:S41-S45.

17. van den Brandhof WE, Kroes ACM, Bosman A, et al. Reporting virus diagnostics in the Netherlands: representativeness of the virological weekly reports in Dutch. Infect Bull. 2002;13:110 -113. Available at: http:// www.rivm.nl/infectieziektenbulletin/bul1304/vir_diagnostiek.html. Accessed April 11, 2008.

18. Poisson Regression_UCLA Academic Technology Services website_. Available at: http://www.ats.ucla.edu/stat/stata/dae/poissonreg.htm. Accessed August 28, 2008.

19. Yorita KL, Holman RC, Steiner CA, et al. Severe bronchiolitis and respiratory syncytial virus among young children in Hawaii. Pediatr Infect Dis J. 2007;26:1081-1088.

20. Nagayama Y, Tsubaki T, Nakayama S, et al. Gender analysis in acute bronchiolitis due to respiratory syncytial virus. Pediatr Allergy Immunol. 2006;17:29 -36.

21. List of countries by population density. Available at: http://en.wikipedia.org/ wiki/List_of_countries_and_dependencies_by_population_density. Accessed March 3, 2009.

22. Rechsteiner J, Winkler KC. Inactivation of Respiratory Syncytial Virus in Aerosol. J Gen Virol. 1969;5:405-410.

23. Cannell JJ, Zasloff M, Garland CF, et al. On the epidemiology of influenza. Virol J. 2008;5:29.

24. Najada AS, Habashneh MS, Khader M. The frequency of nutritional rickets among hospitalized infants and its relation to respiratory diseases. J Trop Pediatr. 2004;50:364 -368.

25. UV-straling in Nederland. Available at: http://www.milieuennatuurcompendium.nl/indicatoren/nl0220-

UV-straling-in-Nederland.html?i_9-84. Accessed February 13, 2009.

26. Moise AF, Aynsley R. Ambient ultraviolet radiation levels in public shade settings. Int $\mathrm{J}$ Biometeorol. 1999;43:128 -138.

27. Koskela $\mathrm{H}$, Tukiainen $\mathrm{H}$. Facial cooling, but not nasal breathing of cold air, induces bronchoconstriction: a study in asthmatic and healthy subjects. Eur Respir J. 1995;8:2088 -2093.

28. Koskela HO. Cold air-provoked respiratory symptoms: the mechanisms and management. Int $\mathrm{J}$

Circumpolar Health. 2007;66:91-100.

29. Goddard NL, Cooke MC, Gupta RK, et al. Timing of monoclonal antibody for seasonal RSV prophylaxis in the United Kingdom. Epidemiol Infect. 2007;135:159 -162.

\section{FIGURES}

A

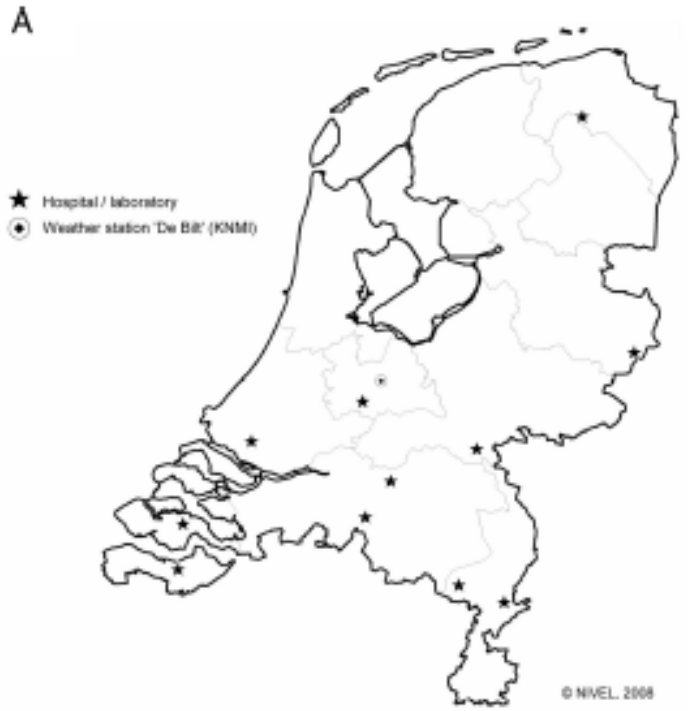

FICURE 1. Geographical distribution of the laboratories that reported RSV data (A), and the number of RSV cases in the different postal codes reported by the laboratories in the period 1998-2005 (B).
B

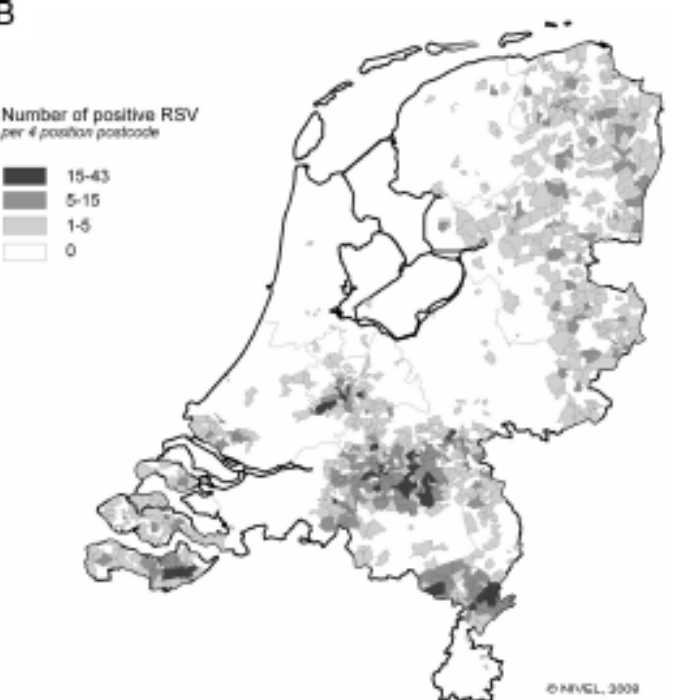


Meerhoff, T.J., Paget, W.J., Kimpen, J.L., Schellevis, F. Variation of respiratory syncytial virus and the relation with meteorological factors in different winter seasons. Pediatric Infectious Disease Journal: 2009, 28(10), 860866

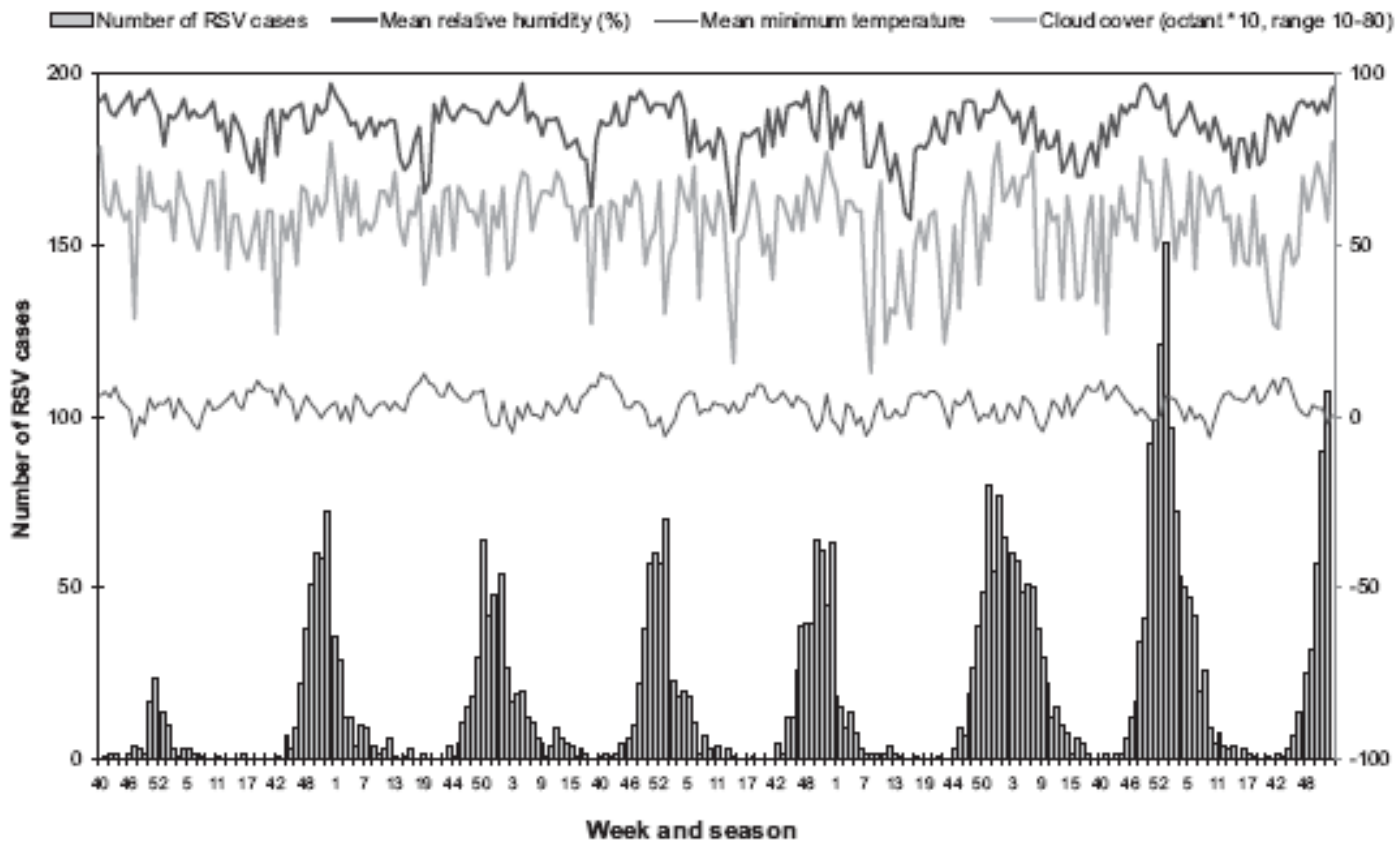

FICURE 2. RSV detections and minimum temperature $\left({ }^{\circ} \mathrm{C}\right)$, relative humidity $(\%)$, and cloud cover $\left(\right.$ octant $\left.{ }^{\star} 10\right)$ in the winter periods 1998-2005 in the Netherlands. The weekly mean values of the weather variables are presented on the $y$ axis.

\section{TABLES}

TABLE 1. Baseline Laboratory/Hospital and Patient Characteristics in the Period 1998 to 2005

\begin{tabular}{|c|c|c|c|c|c|}
\hline Laboratory/Hospital & $\begin{array}{l}\text { Period Reporting in Winter } \\
\text { Seasons }\end{array}$ & Na Tosts & $\begin{array}{l}\text { No. Positive ESV } \\
\text { Tosts (\&) }\end{array}$ & $\begin{array}{l}\text { Median Age in Mo } \\
\text { (Range) }\end{array}$ & $\begin{array}{l}\text { Gender } \\
(\% \text { Mole })\end{array}$ \\
\hline Bosch Medisch Centrum, Den Boech & $1998 / 1999-2004 / 2005$ & 2225 & $1000(49 \%)$ & $4(0-149)$ & 57 \\
\hline Canisius Wilbelmina boepital, Nijmegen & $1999 / 2000-20002 / 20003$ & 803 & $274(22 \%)$ & $4(0-44)$ & 84 \\
\hline Laboratory for infoctious disareos, Groningen & $2002 / 2008-2008 / 2006$ & 2660 & $751(28 \%)$ & $4(0-975)$ & 61 \\
\hline $\begin{array}{l}\text { Laboratcrium Microbiologie Twrente, Achtorthook, } \\
\text { Enschede }\end{array}$ & $\begin{array}{l}20002001,2002 / 2008 \\
2005 / 2006\end{array}$ & 600 & $233(25 \%)$ & $5(0-86)$ & 64 \\
\hline Ruwaard van Putten Hospital, Spijkenisse & $2001 / 2000-2008 / 2006$ & 241 & $123(36 \%)$ & $4(0-39)$ & 57 \\
\hline St. Antonius Hospital, Nierwegein & $1998 / 1999-2005 / 2006$ & 1001 & $293(39 \%)$ & $4(0-965)$ & 39 \\
\hline St. Elisabeth Hospital, Tilburg & $2002 / 2008-2008 / 2006$ & 720 & $283(25 \%)$ & $3(0-43)$ & 35 \\
\hline St. Jans Gasthuis, Weert & $1998 / 1999-2005 / 2006$ & 415 & $100(39 \%)$ & $4(0-40)$ & 00 \\
\hline St. Laurentius Hoepital, Roermond & $1998 / 1999-2005 / 2006$ & 890 & $416(47 \%)$ & $5(0-85)$ & 55 \\
\hline Streeklaboratorium Zeeland. Terneuzen & $1998 / 1999-2005 / 2006$ & 683 & $208(20 \%)$ & $5(0-39)$ & 57 \\
\hline Streoklaboratorium Zeeland, Goes & $1999 / 2000-2005 / 2006$ & 198 & $101(52 \%)$ & $3(0-52)$ & 65 \\
\hline Total & & 10672 & $4002(38 \%)$ & & \\
\hline
\end{tabular}

TABLE 2. Overview Seasonality RSV Activity and Meteorological Variables by Winter Season for the Period 1998-2005

\begin{tabular}{|c|c|c|c|c|c|c|c|c|c|c|c|c|}
\hline \multirow[t]{2}{*}{$\mathrm{Y}_{\mathbf{r}}$} & \multirow[t]{2}{*}{$\begin{array}{c}\text { RSV } \\
\text { Coses" }\end{array}$} & \multirow[t]{2}{*}{$\begin{array}{l}\text { No. } \\
\text { Labs }\end{array}$} & \multirow[t]{2}{*}{$\begin{array}{c}\text { Wk } \\
\text { Onset }\end{array}$} & \multirow[t]{2}{*}{$\begin{array}{l}\text { Wk } \\
\text { Poak }\end{array}$} & \multirow[t]{2}{*}{$\begin{array}{l}\text { Wk } \\
\text { Offiot }\end{array}$} & \multirow[t]{2}{*}{$\begin{array}{c}\text { Wk } \\
\text { Duration }\end{array}$} & \multicolumn{2}{|c|}{$\begin{array}{l}\text { Minimum } \\
\text { Temperature } \\
\text { (deg Celsius) }\end{array}$} & \multicolumn{2}{|c|}{$\begin{array}{l}\text { Relative } \\
\text { Humidity ( }(\%)\end{array}$} & \multicolumn{2}{|c|}{$\begin{array}{l}\text { Cloud Corer } \\
\text { in Oetants }\end{array}$} \\
\hline & & & & & & & Onset & Peak & Onset & Peak & Onset & Poak \\
\hline $1998-1909$ & 95 & 5 & 50 & 51 & 2 & 5 & 5.4 & 22 & 95 & 91 & 7 & 6 \\
\hline $1999-2000$ & 462 & 7 & 44 & 52 & 12 & 22 & 6.1 & 18 & 87 & 90 & 5 & 6 \\
\hline $2000-2001$ & 452 & 8 & 45 & 80 & 15 & 24 & 5.8 & 78 & 89 & 86 & 7 & 7 \\
\hline $2001-2002$ & 410 & 8 & 43 & 51 & 11 & 22 & 8.6 & -28 & 91 & 91 & 6 & 5 \\
\hline $2002-2003$ & 439 & 11 & 42 & 30 & 13 & 25 & 5.2 & -4.1 & 90 & 80 & 6 & 6 \\
\hline $2002-2004$ & 811 & 10 & 47 & 51 & 17 & 27 & 7.6 & -02 & 92 & 89 & 7 & 5 \\
\hline $2004-2005$ & 917 & 10 & 45 & 32 & 11 & 20 & 4.5 & 03 & 88 & 90 & 6 & 5 \\
\hline $2005-2006$ & 353 & 9 & 44 & 52 & n.a. & n.a. & 10.7 & -2.1 & 82 & 89 & 5 & 6 \\
\hline Median & 446 & 9 & 45 & 51 & 12 & 22 & 6.0 & 0.1 & 90 & 90 & 6 & 6 \\
\hline Mean & 492 & 9 & 45 & $s_{1}$ & 12 & 21 & 6.7 & 0.4 & 89 & 88 & 6 & 6 \\
\hline \multicolumn{13}{|c|}{ 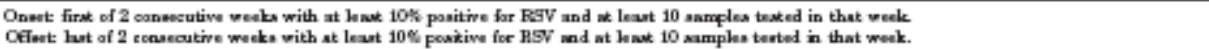 } \\
\hline \multicolumn{13}{|c|}{ 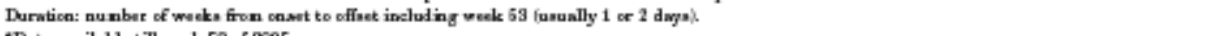 } \\
\hline $\begin{array}{l}\text { :Date availathe } \\
\text { 'Original dete, }\end{array}$ & ill woek 62 & & & & & & & & & & & \\
\hline
\end{tabular}


Meerhoff, T.J., Paget, W.J., Kimpen, J.L., Schellevis, F. Variation of respiratory syncytial virus and the relation with meteorological factors in different winter seasons. Pediatric Infectious Disease Journal: 2009, 28(10), 860866

TABLE 3. Multiple Linear Regression Analysis With the Number of RSV Cases as the Dependent Variable, and Minimum Temperature, Relative Humidity, and Cloud Cover as Independent Variables for Different Time Lags Expressed in Standardized Beta Coefficients and Explained Variance $\left(\boldsymbol{R}^{2}\right)$

\begin{tabular}{|c|c|c|c|c|}
\hline Woekly Number RSV Coeas & $\begin{array}{l}\text { Weekly Mean Minimum. } \\
\text { Tomperature }\end{array}$ & $\begin{array}{l}\text { Weekly Mean Relative } \\
\text { Humidity }\end{array}$ & $\begin{array}{l}\text { Weekly Mean Cloud } \\
\text { Corer }\end{array}$ & $R^{2}$ \\
\hline No lag & $-0.221^{*}$ & $0.203^{*}$ & $0.141^{\circ}$ & 0.209 \\
\hline Lag 1 wk & $-0.243^{*}$ & $0.282^{*}$ & 0.123 & 0.201 \\
\hline $\log 2$ wk & $-0.2223^{*}$ & $0.258 *$ & 0.046 & 0.206 \\
\hline $\operatorname{Lag} 3$ wk & -0.15364 & $0.404^{*}$ & -0.014 & 0.185 \\
\hline $\log 4 \mathrm{wk}$ & -0.043 & $0.433^{*}$ & -0.071 & 0.165 \\
\hline
\end{tabular}

TABLE 4. Multiple Linear Regression Analysis With the Number of RSV Cases as the Dependent Variable, Interaction Between Minimum Temperature and Relative Humidity*, Minimum Temperature, Relative Humidity, and Cloud Cover As Independent Variables for Different Time Lags Expressed in Standardized Beta Coefficients and Explained Variance $\left(R^{2}\right)^{\prime}$

\begin{tabular}{|c|c|c|c|c|c|}
\hline $\begin{array}{l}\text { Weokly Number } \\
\text { RSV Coeas }\end{array}$ & $\begin{array}{c}\text { Interaction Minimum } \\
\text { Temperature and Relotive Humidity }^{\text {I }}\end{array}$ & $\begin{array}{c}\text { Wookly Mean } \\
\text { Minimum Temperature }\end{array}$ & $\begin{array}{c}\text { Wookly Mean } \\
\text { Relative Humidity }\end{array}$ & $\begin{array}{l}\text { Weokly Maan } \\
\text { Cloud Covor }\end{array}$ & $R^{2}$ \\
\hline No lag & $1.566^{2}$ & 1256 & $0.329^{5}$ & $0.142^{2}$ & 0.227 \\
\hline Lag 1 wk & 1.2591 & 1.120 & 0.3895 & 0.124 & 0.212 \\
\hline $\log 2$ wk & $1.581^{\text {*ै }}$ & 1354 & $0.464^{5}$ & 0.043 & 0.218 \\
\hline Lag 3 wk & 1.329 & 1.183 & $0.487^{5}$ & -0.014 & 0.193 \\
\hline $\log 4$ wk & 1.044 & 0996 & $0.491^{5}$ & -0.071 & 0.166 \\
\hline
\end{tabular}

